\title{
STUDIES OF LUNG VOLUMES AND INTRAPULMONARY MIXING: NOTES ON OPEN-CIRCUIT METHODS, INCLUDING USE OF \\ A NEW PIVOTED TYPE GASOMETER FOR LUNG CLEARANCE STUDIES
}

\author{
By J. B. BATEMAN,1 WALTER M. BOOTHBY, AND H. FREDERIC HELMHOLZ, JR.
}

(From the Mayo Aero Medical Unit and the Division of Physics and Biophysical Research, Mayo Foundation, Rochester, Minn.)

(Received for publication October 18, 1948)

\section{INTRODUCTION}

The measurement of lung volume by an opencircuit method $(1,2)$ is usually based on the redistribution of nitrogen contained in the lungs in such a manner that most of this gas is expelled and measured. Physically, this principle requires only the collection of the exhaled nitrogen in some diluent such as oxygen and the measurement of total volume and nitrogen concentration; the quantity of nitrogen involved can then be computed. In the usual procedure the subject breathes oxygen for a set period, the total expired air being collected in a gasometer; then the connecting tubes are washed with more oxygen and the final volume and nitrogen concentration in the gasometer are measured.

Such a method could be extended to the study of the nitrogen clearance process. The physical conditions which must be satisfied, however, are much more exacting than those which apply to measurement of lung volume. It becomes necessary to determine accurately (1) respiratory volume at various instants during the clearance process and (2) the total amounts of nitrogen in the external system at these instants. These requirements demand modification of existing open-circuit methods in the following particulars : $A$. It is necessary to avoid continuous flow of oxygen by-passing the experimental subject. Only by using a true demand system of oxygen supply can it be assured that all the gas collected has been involved in the tidal movement. $B$. It is necessary either to measure separate points on the clearance curve by doing several experiments, or to arrange for serial sampling of the expired gas, with simultaneous measurement of volume. The

\footnotetext{
1 Present address: Physical and Chemical Division, Research and Development Dept., Camp Detrick, Frederick, Maryland.
}

latter expedient, which is preferable, implies in turn (1) the presence in the gasometer of some device to ensure rapid mixing of the gases introduced and (2) the elimination, as far as may be feasible, of tubes connecting the subject with the gasometer. If the latter condition is not satisfied, part of the gas exhaled in any breath will not reach the gasometer until the succeeding breath.

During experimental work described elsewhere $(3,4)$ some 30 modifications of the open-circuit method have been used in the measurement of lung clearance curves. It will perhaps be of value, in view of this extensive experience, to indicate the ways of meeting the foregoing technical requirements which have proved most reliable. This paper deals solely with the physical problems of measuring the volume and composition of expired gas and neither with physiologic sources of error nor with the interpretation of the data. Two distinct procedures, the "end-point sampling" method and the "serial sampling" method, will be described. The latter is greatly to be preferred, but it involves the use of special equipment.

\section{THE END-POINT SAMPLING METHOD}

Experimental arrangement. Figure 1 represents the arrangement which has been found most satisfactory. Oxygen is supplied from high pressure tanks after reduction to 100 pounds per square inch. This serves as the input line for a Pioneer dilutor-demand oxygen regulator, type AN6004-1, which has been modified by removing the dilutor cap and handle and the aneroid unit and sealing the opening with a gasket and bakelite plate. Thus the valve supplies only pure tank oxygen. $^{2}$ Since the operating suction is appreci-

2 We are indebted to the National Bureau of Standards and to Lieutenant Commander Allison of the Naval Bureau of Aeronautics for this regulator. 


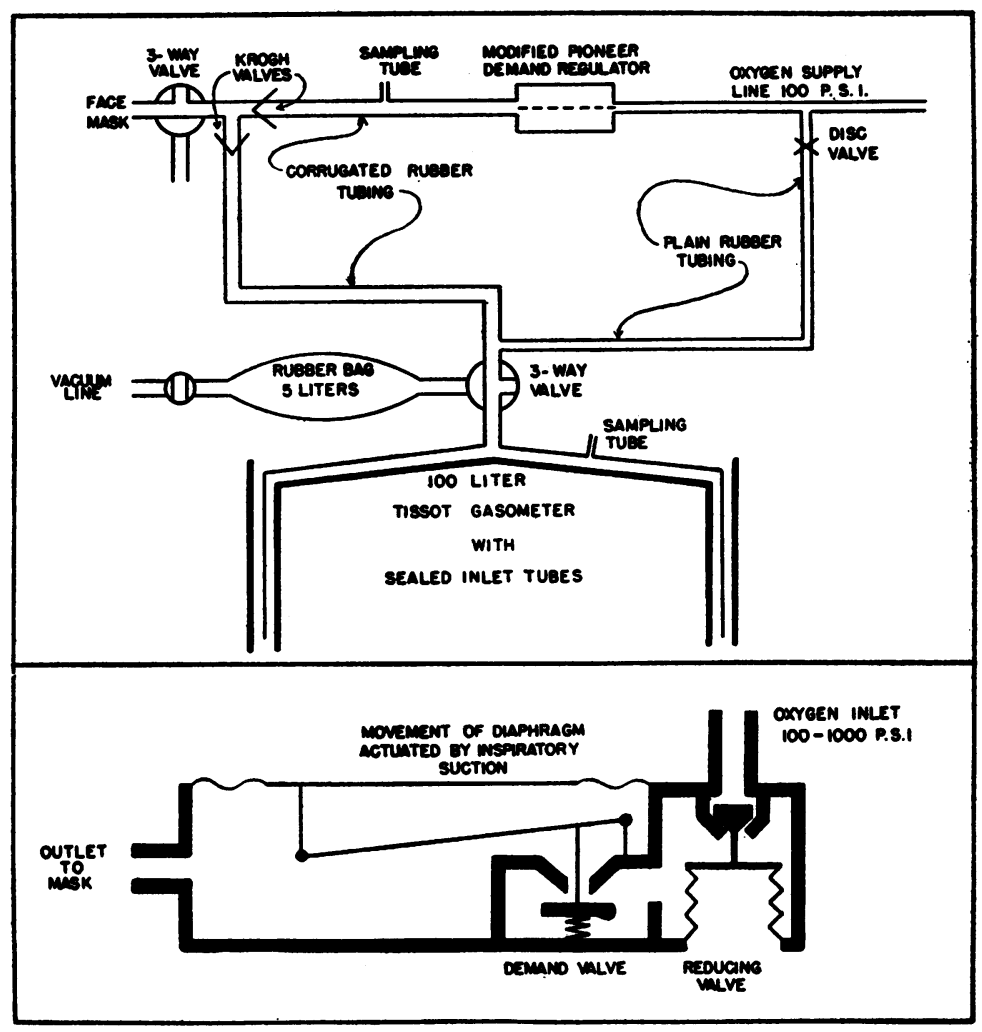

Fig. 1. The End-Point Sampling Method

Above: Open-circuit assembly for collecting nitrogen expelled during breathing of oxygen. Below: Diagram (schematic) of modified oxygen demand regulator.

able the regulator is loaded with a 15 -gm. weight placed on the large diaphragm indicated in the lower portion of Figure $1 .^{3}$ The output side of the demand regulator is connected by large corrugated rubber tubing to a Krogh valve, to a three-way hand-operated valve of large bore and finally to the face mask worn by the subject. At a point slightly distal to the three-way valve, the inspiratory line communicates with the tube through which the expired gases pass, by way of a second Krogh valve, to the gasometer bell. The gasometer is of the Tissot type, of 100-liter capacity, modified by sealing the inlet tubes at their point of entry into the main chamber. This appreciably reduces the dead space. Welded to the roof of

${ }^{3}$ Evidence has been obtained that a certain amount of by-passing occurred in some of the experiments reported in the following papers as a result of failure of the valve to close completely when operated by persons with certain types of respiratory pattern. This source of error has now been obviated. the gasometer bell is a second manual three-way valve of large bore with a side-arm connected to a 5-liter rubber bag and vacuum line. The bag is used at the end of each experiment for mixing the collected expired gas in the gasometer, by being successively filled and emptied. The wire carrying the counterweight of the gasometer is supplied with a pen which indicates volume on a moving drum, not shown in Figure 1, during the collection of expired gas. The by-pass from the high-pressure oxygen supply to the gasometer indicated in the diagram serves for initial washing of the apparatus.

Attention may be drawn to (1) provision of a sampling tube for checking the composition of inspired gas, and (2) the valve assembly, consisting of two Krogh valves welded into a compact unit.

Analytic method. A modified Haldane method of gas analysis was used, the nitrogen residue being measured as the volume increment brought 
about after mixing with a larger measured volume of stored nitrogen. Duplicate analyses are usually reproducible to within 0.001 ( 0.10 per cent nitrogen).

The accuracy with which a given amount of nitrogen can be estimated after dilution with oxygen was investigated by progressively diluting a known amount of air (measured by displacement of water) in a gasometer of known dead space with measured amounts of oxygen and comparing the measured decreases of nitrogen concentration with those calculated from the volumes mixed (Table I). It seems fair to conclude from the final column of Table $I$ that at no point in a clearance curve is the error in the total amount of nitrogen measured likely to exceed $100 \mathrm{ml}$. from this particular source of error; usually it will be much less. The accuracy seems to be greatest when the nitrogen fraction in the gasometer is 1 to 3 per cent.

Accuracy of volume measurements. In the 100-liter Tissot gasometer, a movement of $1 \mathrm{~cm}$. indicates a change of volume of about 2 liters. The scale can be read to about $0.25 \mathrm{~mm}$., or 50 $\mathrm{ml}$. This is adequate for most purposes provided it can be proved possible to determine the conditions of temperature and humidity to which the measured value applies. It has been found in repeated tests that the volume of expired air received by the gasometer does not undergo any observable change over a period of several minutes. Presumably, the gas leaving the subject at $37^{\circ} \mathrm{C}$ and saturated with water vapor is almost immediately cooled to the temperature of the gasometer and the corresponding pressure of saturated aqueous vapor is established. It follows

TABLE I

Gasometric estimation of nitrogen diluted with varying quantities of oxygen *

\begin{tabular}{|c|c|c|c|c|c|c|c|}
\hline $\begin{array}{l}\quad(1) \\
\text { Volume of air } \\
\text { originally in } \\
\text { gasometer }\end{array}$ & $\begin{array}{l}(2) \\
\begin{array}{c}\text { Nitrogen re- } \\
\text { moved in } \\
\text { samples }\end{array}\end{array}$ & $\begin{array}{l}(3) \\
\text { Corrected vol- } \\
\text { ume of air } \\
\text { present } \\
\left(\mathrm{V}_{\text {air }}\right)\end{array}$ & $\begin{array}{l}\text { (4) } \\
\text { Total volume } \\
\text { of gas in } \\
\text { gasometer } \\
(\mathrm{D}+\mathrm{V})\end{array}$ & $\begin{array}{c}\text { Measured } \mathrm{N}_{2} \\
\text { fraction in } \\
\text { gasometer } \\
\left(\mathrm{fN}^{\prime \prime \prime}\right)\end{array}$ & $\begin{array}{l}(6) \\
\text { Calculated } \\
\text { volume of air } \\
\text { in gasometer }\end{array}$ & \multicolumn{2}{|c|}{$\begin{array}{l}(7) \\
\text { Differences between analytic } \\
\text { and volumetric volumes of air }\end{array}$} \\
\hline $\begin{array}{c}c m .^{3} \\
1,112\end{array}$ & $\begin{array}{c}c m .^{3} \\
0 \\
22 \\
9 \\
4\end{array}$ & $\begin{array}{c}c m .^{3} \\
1,112 \\
1,090 \\
1,081 \\
1,077\end{array}$ & $\begin{array}{c}\mathrm{cm} \cdot{ }^{3} \\
13,640 \\
32,800 \\
73,440 \\
93,620\end{array}$ & $\begin{array}{l}0.0697 \\
0.0290 \\
0.0131 \\
0.0106\end{array}$ & $\begin{array}{c}\mathrm{cm} .^{3} \\
1,172 \\
1,127 \\
1,042 \\
1,032\end{array}$ & $\begin{array}{l}\mathrm{cm} \cdot{ }^{3} \\
+\quad 60 \\
+\quad 37 \\
-\quad 39 \\
-\quad 45\end{array}$ & $\begin{array}{c}\text { per cent of (3) } \\
+5.4 \\
+3.4 \\
-3.6 \\
-\quad 4.2\end{array}$ \\
\hline 2,104 & $\begin{array}{r}0 \\
44 \\
17 \\
8\end{array}$ & $\begin{array}{l}2,104 \\
2,060 \\
2,043 \\
2,035\end{array}$ & $\begin{array}{l}12,530 \\
32,800 \\
73,360 \\
93,620\end{array}$ & $\begin{array}{l}0.1399 \\
0.0522 \\
0.0248 \\
0.0198\end{array}$ & $\begin{array}{l}2,192 \\
2,091 \\
2,129 \\
2,124\end{array}$ & $\begin{array}{l}+88 \\
+31 \\
+86 \\
+89\end{array}$ & $\begin{array}{l}+4.2 \\
+1.5 \\
+4.2 \\
+4.4\end{array}$ \\
\hline 1,115 & $\begin{array}{r}0 \\
23 \\
9 \\
4\end{array}$ & $\begin{array}{l}1,115 \\
1,092 \\
1,083 \\
1,079\end{array}$ & $\begin{array}{l}12,530 \\
32,900 \\
73,360 \\
93,620\end{array}$ & $\begin{array}{l}0.0744 \\
0.0285 \\
0.0133 \\
0.0097\end{array}$ & $\begin{array}{r}1,151 \\
1,109 \\
1,060 \\
925\end{array}$ & $\begin{array}{l}+36 \\
+17 \\
-23 \\
-154\end{array}$ & $\begin{array}{l}+3.2 \\
+1.6 \\
-2.1 \\
-14.3\end{array}$ \\
\hline 2,100 & $\begin{array}{r}0 \\
44 \\
17 \\
8\end{array}$ & $\begin{array}{l}2,100 \\
2,056 \\
2,039 \\
2,031\end{array}$ & $\begin{array}{l}12,530 \\
32,800 \\
73,440 \\
93,620\end{array}$ & $\begin{array}{l}0.1379 \\
0.0520 \\
0.0245 \\
0.0190\end{array}$ & $\begin{array}{l}2,160 \\
2,083 \\
2,104 \\
2,029\end{array}$ & $\begin{array}{l}+60 \\
+\quad 27 \\
+\quad 65 \\
-\quad 2\end{array}$ & $\begin{array}{l}+\quad 2.9 \\
+\quad 1.3 \\
+\quad 3.2 \\
-\quad 0.1\end{array}$ \\
\hline
\end{tabular}

* Procedure: The gasometer dead space is originally filled with tank oxygen. A known volume of air is admitted to the gasometer by displacement with a weighed amount of water in an Erlenmeyer flask (column 1). A known volume of oxygen is then added, the gasometer volume is read (column 4) and a sample is removed for analysis (column 5). Then further oxygen is added and the procedure is repeated, the original volume of air in the gasometer being corrected at each stage for the amount removed in the sample (column 2). The corrected volume of air (column 3 ) can be compared with that calculated from the nitrogen analyses (column 6).

$$
\mathrm{V}_{\mathrm{air}}=\frac{(\mathrm{V}+\mathrm{D})\left(\mathrm{fN}^{\prime \prime \prime}-\mathrm{fN}\right)}{0.791-\mathrm{fN}}
$$

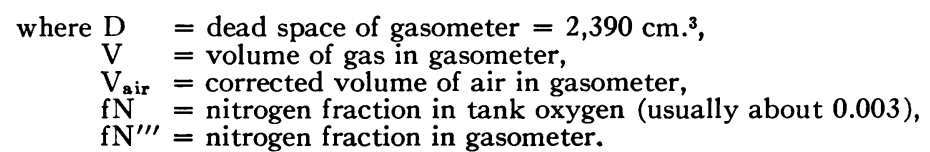


also that no measurable errors are introduced by transfer of gas to or from the water in the gasometer.

Gasometer dead space. Even when measures were taken to reduce the dead space of the Tissot gasometer, the value remained in excess of 2 liters. This is undesirably large and its presence has reduced the accuracy of our measurements in the early part of the lung clearance curve. A more serious drawback is the fact that this dead space is less constant than might be desired, since the position of the gasometer bell when the gasometer is "empty" is variable. This is difficult to eradicate in a gasometer of the Tissot type.

Procedure in end-point sampling method. For some hours before the experiment is started, the entire system is washed with a slow stream of cylinder oxygen. Analyses of the gas in various parts of the system are made. The gasometer is then emptied, the rubber bag is evacuated, and the three-way valve to the gasometer is oriented as shown in Figure 1. The subject is connected to the apparatus with a suitable face mask, with the three-way valve so turned that he is able to breathe room air. After doing this for a short time, he rapidly turns the three-way valve at the end of a normal expiration so as to be brought into connection with the oxygen supply system and the gasometer. He breathes oxygen for the desired number of breaths-ten for example-and at the end of the tenth exhalation, turns his threeway valve back to the original position. A volume reading is taken on the gasometer and the connecting tubes in the expiratory line are flushed with 10 liters of oxygen. The three-way valve on the gasometer is turned so that the rubber bag fills itself from the gasometer contents; it is then emptied by hand and filled again, and the cycle is repeated ten times. The gas is then deemed adequately mixed and samples are collected over mercury in a $100-\mathrm{ml}$. tube. In order to get further points on the clearance curve, the system is again washed with oxygen and after a suitable intervening period of at least 30 minutes, during which the subject breathes air, the entire procedure is repeated.

\section{THE SERIAL SAMPLING OF COLLECTED EXPIRED AIR}

The study of lung clearance curves by the method described in the preceding section is at best a laborious procedure. In any extended investigation, it is desirable to develop methods for detailed recording of a single clearance process. Such a method, which would involve taking a series of instantaneous samples of mixed expired gas, would have further advantages, including the reduction of errors resulting from variations in the initial lung volume. For this and other reasons, methods for serial sampling have been devised.

Four new requirements must receive attention in connection with serial sampling: 1. Provision for rapid mixing of gases must be made. so that any sample is truly representative of the entire contents of the gasometer. 2. The volume of the tubes connecting the subject with the gasometer must be reduced because it represents a volume of expired air which, at every exhalation, fails to enter the gasometer and is thus unable to contribute to the composition of the mixed expired gas. 3. An improved sampling procedure is required. since it is necessary to take samples rapidly and at frequent intervals. 4. The gasometer dead space should be reduced.

A NEW GASOMETER ASSEMBLy FOR LUNG CLEARANCE STUdiES BY SERIAL SAMPLING

The gasometer. A new gasometer with associated equipment has been designed with the foregoing considerations in mind, together with the following additional points which appeared important: (a) low inertia of moving parts, (b) convenient and accurate recording of collected gas volume and $(c)$ capacity large enough to hold most of the air expired during lung clearance but small enough for adequate accuracy in the recording of volume and also small enough to make it convenient to conduct a clearance measurement in two parts, since the final portion of the clearance curve can be more accurately determined in this manner than would be possible in a single protracted period of collection.

The plans for the new gasometer were placed in the hands of the Waters Conley Company, Rochester, Minnesota, which was responsible for mechanical details and for the construction of the apparatus.

A gasometer of the pivoted type $(5,6)$ appeared to offer decisive advantages, the form being such as to permit close approach of the subject. so that the dead space of the connecting tube can 

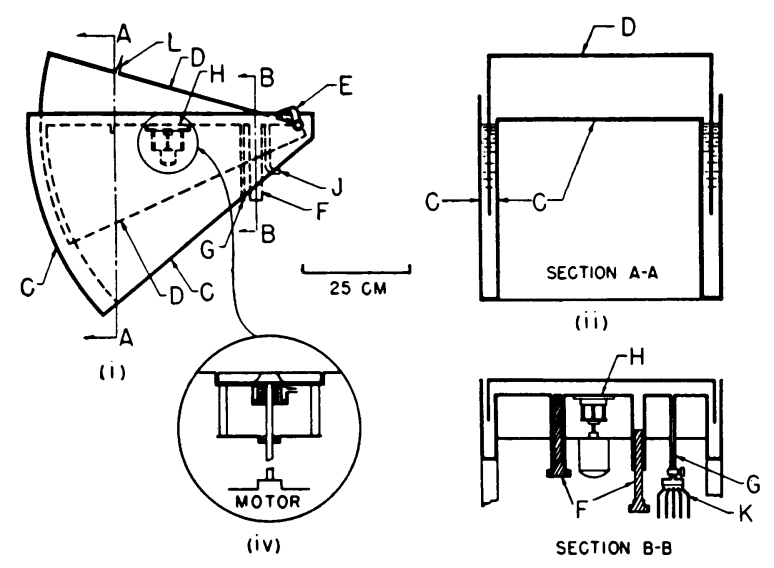

(iii)

Fig. 2. Pivoted Type Gasoneter

Side view and sections showing positions of gas agitator, inlet tubes and sampling device. See text.

be reduced to a few cubic centimeters. Such an apparatus also appeared amenable to fine mechanical construction, so that the internal dead space could be much reduced. Moreover, since the bell is not freely suspended but can be accurately and rigidly pivoted, this dead space should be highly reproducible. Added to these advantages is the ease with which the necessary mechanical linkages can be made for recording gas volume.

The layout of the apparatus can be gathered from Figures 2 and 3. The gasometer bell consists of a wedge-shaped shell of about 60 liters capacity (Figure 2, D) made of sheet aluminum (roof $3 \mathrm{~mm}$. thick; side walls $0.75 \mathrm{~mm}$.) pivoted at one end (Figures 2 and 3, E) with "New Departure" precision ball bearings. It articulates in a water-filled well of the form indicated by $\mathrm{C}$ (Figure 2), which thus takes the form of a rectangular moat bounding a rectangular floor of sheet brass (Figure 2 [ii]). When the bell and the trough articulate, the volume of gas between them is completely enclosed by a water seal. The floor is pierced by several holes. These are conveniently placed near the axle of the machine. The centrally situated tube, J (Figure 2), of internal diameter $1.3 \mathrm{~cm}$., serves for the introduction of expired gas. A narrow sampling tube, $G$, of internal diameter $0.3 \mathrm{~cm}$., passes to the lucite distributor (see also page 684). Two wide apertures, $\mathrm{F}$, are included, so as to make the apparatus rapidly and conveniently adaptable for use in open-circuit or closed-circuit measurements of metabolic rate. Normally, these tubes are kept closed by brass plugs which pass in as far as the level of the floor of the gasometer chamber, thus eliminating additional dead space. Finally, an opening, $\mathrm{H}$ (Figure 2), in the center of the floor carries the driving shaft of a circulating fan set in a depression $10 \mathrm{~cm}$. in diameter and $0.6 \mathrm{~cm}$. deep. This fan, of centrifugal type. and its watersealed bearing are shown in more detail in Figure 2 (iv).

The two recording systems are shown in Figure 3. For photographic recording, the horizontal axis about which the gasometer bell moves is linked by means of a flexible cable to a vertical axle, U, supported by two precision ball bearings and provided with a mirror (Figure 3 [iii]). For mechanical recording, a wire attached to the lowest peripheral point. $\mathrm{M}$, of the gasometer bell passes over a fixed pulley, $\mathrm{N}$, to the ink-writer pulley, $\mathrm{P}$, and thence to a counterweight, $\mathrm{O}$, which is adjusted to keep the gasometer bell very nearly balanced in all positions. The method of attachment of the recording wire to the gasometer bell is of some importance, since the effective point of attachment is determined by the tangent from the pulley, $N$, to the circular arc defined by the end of the gasometer bell. The point of attachment is therefore effectively constant for all positions of the bell, so that a linear relation between volume and recorded deflection is assured. A system of gears introduces the possibility of amplifying the volume record in accordance with the following figures: for direct recording, 1 liter volume change produces $6.5 \mathrm{~mm}$. deflection; for amplified

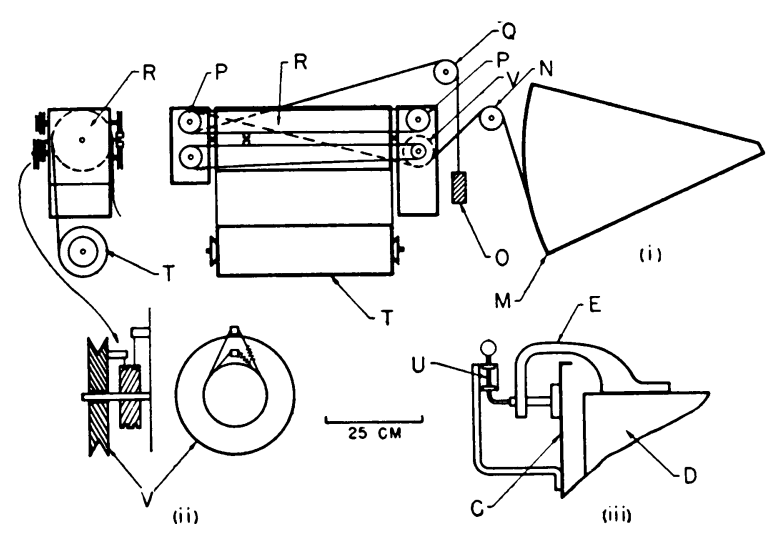

Fili. 3. Detall.s of Recording Mechaxisms of Pivoted TyPe Gasometer

(See text.) 


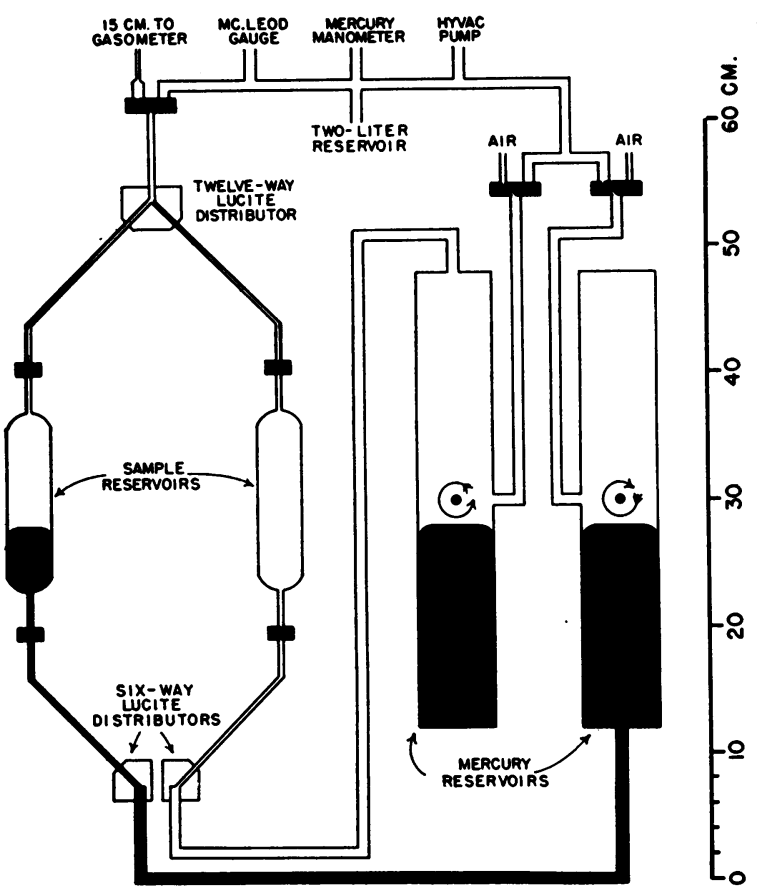

Fig. 4. Experimental Arrangement Used for Collecting Serial Samples of Expired Air in Evacuated SAMPle Tubes

Operation described in text.

recording, the deflection is $25 \mathrm{~mm}$. Furthermore, a clutch system operated by the pulley, V, drawn in detail in Figure 3 (ii), enables the lower pen to operate as an indicator of total ventilation. This is not used in lung clearance measurements, but is useful in closed-circuit metabolism studies.

The entire apparatus is mounted with adjustable clamps on two steel pillars $7 \mathrm{~cm}$. in diameter attached to a wheel base, vertical adjustment being facilitated by counterweights.

Sampling procedure. Samples from the gasometer are collected over mercury in evacuated 100$\mathrm{ml}$. Pyrex tubes. Twelve such tubes are connected through a lucite distributor to the sample tube of the gasometer (Figure 4). The tubes are evacuated by a Cenco pump before the experiment is commenced and the rest of the system, consisting of the dead space of the distributor, the 2-liter reservoir, and various mercury traps and connecting tubes, is kept evacuated throughout the experiment. When a sample is to be taken, the entire distributor is filled with gas from the gasometer; then the appropriate sample tube is opened and closed. Immediately thereafter, the distribu- tor is once more connected to the vacuum line and is evacuated in time for the next sample. At the end of the experiment, mercury is admitted to the sample tubes so as to bring the samples to atmospheric pressure and reduce the danger of inboard leaks.

The mercury reservoirs shown in Figure 4 were necessary in order to free the mercury from air and to obviate the danger of contamination by inward leakage of air through flexible connecting tubes. It was found that both rubber and plastic tubing are permeable to air, so that without special precautions, large analytic errors were caused by air leaking into the mercury and thus being transferred to the gas samples. The mercury reservoirs were designed in such a way that during the preliminary removal of air from the system all flexible connecting tubes could be emptied and evacuated. The mercury itself could be agitated by inverting

\section{NITROGEN ELIMINATION}

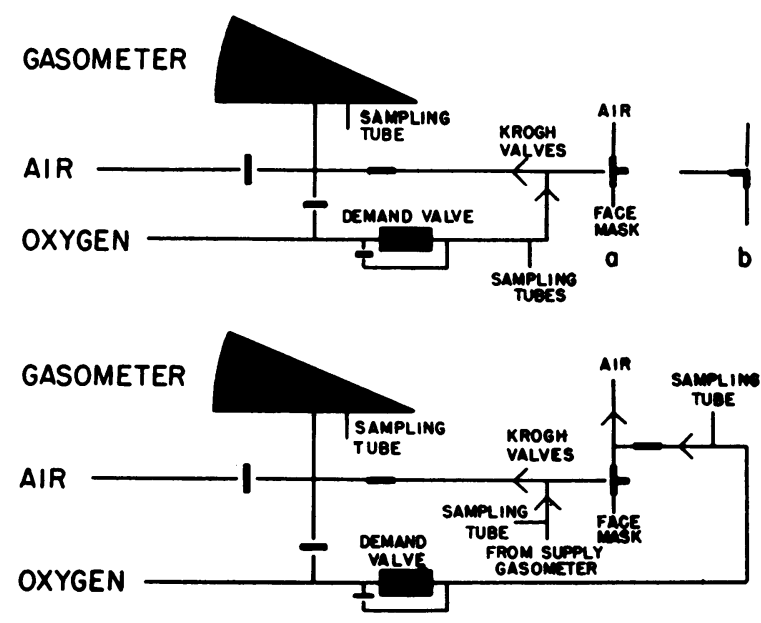

\section{NITROGEN RETENTION}

Fig. 5. Serial Sampling Arrangement Used in Study of Elimination and Retention of Nitrogen BY THE LUNG

(1) By collecting expired gas during the breathing of pure oxygen, (2) By collecting expired gas during breathing of air following prolonged inhalation of oxygen. Connecting tubes are represented by thin continuous lines. Thick lines indicate the presence of hand-operated valves. Arrows represent Krogh valves. The gasometer is a pivoted type apparatus of 60 -liter capacity provided with a fan to accelerate mixing of gas collected. Serial samples of total expired gas are taken through the sampling tube in the floor of the gasometer, using the distributor shown in Figure 4. 
the reservoirs by rotation about a central axle as indicated by the arrows in Figure 4. As soon as the reservoirs were restored to their original position and mercury was again introduced into the flexible tubing, it was possible to admit air to the reservoirs and to maintain the mercury at or above atmospheric pressure. The entire system, including the lucite distributor, was tested routinely for leakage by reducing the pressure to about $0.1 \mathrm{~mm}$. of mercury and observing its constancy with a McLeod gauge (Stokes, type 276 AA).

Dead space. The volume of gas in the gasometer and fixed connecting tubes when the moving shell is completely collapsed was measured both by filling this volume with tank oxygen and diluting with a known amount of air or nitrogen, and also by filling with air and diluting with tank oxygen. Concordant and reproducible values were obtained. The volumes of the conducting passages distal to the Krogh valve assembly and of the connections from the Krogh valve assembly to the face mask (Figure 5) were determined from their physical dimensions. The dead space of the face mask was estimated in several persons by filling it with water and measuring the amount of water remaining after the mask had been placed over the face. As it was not feasible to perform this type of measurement on every subject, a single average value was used throughout. The three dead-space volumes, measured in milliliters, were (1) "internal" dead space of gasometer, $d, 544 \mathrm{ml}$, with which may be contrasted the value of about $2,000 \mathrm{ml}$. in the modified Tissot gasometer used in the "endpoint sampling" experiments; (2) "external" gasometer dead space, $D, 85 \mathrm{ml}$; (3) external "respiratory" dead space, $d_{\mathrm{e}}, 150 \mathrm{ml}$. (volume of mask and connecting tubes as far as Krogh valve assembly).

Mixing of expired gas in gasometer. During the experiments reported elsewhere $(3,4)$ the fan used for mixing the expired gases was operated by a small motor rated at 3,600 r.p.m. This fan was later found to be erratic in performance and mixing was not sufficiently rapid. The motor was replaced by one rated at 7,000 r.p.m. connected through a Variac transformer, and the rate of mixing was measured as a function of the transformer setting. The sampling error attained an acceptably low value with an undetermined motor speed somewhat less than 7,000 r.p.m. The magnitude of these sampling errors is discussed elsewhere (4). Assembly; experimental procedure. The final assembly used in lung volume and lung clearance studies is shown in the upper portion of Figure 5, together with the slight modification (lower diagram) when nitrogen retention during the breathing of air is to be measured. The assembly is essentially similar to that used in the end-point sampling method except for the fact that the sampling tube is connected to the evacuated lucite distributor and multiple reservoir system already described. The sampling tube indicated in the oxygen line is for determining the composition of the supply oxygen from time to time and for establishing the absence of air leaks.

The procedure is also similar to that already described, save for changes necessitated by serial sampling. The sampling procedure involves counting of the number of breaths of oxygen, rapid manual operation of the stopcocks in the distributor assembly during the appropriate inspiration, and simultaneous operation of an electric signal which records the spirometer volume on the ink record at the instant of sampling. The technic needs to be rehearsed a few times.

\section{SUMMARY}

The extension of open-circuit methods of measuring lung volumes to a study of lung clearance rates requires certain physical modifications which are enumerated above (see also page 679). The necessary modifications have been embodied in two experimental assemblies and procedures referred to as "end-point sampling" and "serial sampling."

The assembly designed for end-point sampling experiments is composed of standard pieces of equipment, slightly modified. The method, although capable of considerable accuracy, is laborious.

The assembly designed for serial sampling requires a specially designed gasometer of small internal and external dead space, equipped with means for rapid mixing of the expired gases and with attachments for rapid sampling. With such an assembly, lung clearance curves can be obtained in about one-tenth of the time required by the endpoint sampling method. A pivoted type gasometer designed and built for use in the serial sampling 
apparatus, but also suitable for standard spirometric studies by open-circuit or closed-circuit methods, is described.

Experimental procedures are given for the study of pulmonary clearance curves by the two methods.

\section{BIBLIOGRAPHY}

1. Darling, R. C., Cournand, André, Mansfield, J. S., and Richards, D. W., Jr., Studies on intrapulmonary mixture of gases. I. Nitrogen elimination from blood and body tissues during high oxygen breathing. J. Clin. Invest., 1940, 19, 591.

2. Darling, R. C., Cournand, André, and Richards, D.
W., Jr., Studies on the intrapulmonary mixture of gases. III. An open circuit method for measuring residual air. J. Clin. Invest., 1940, 19, 609.

3. Bateman, J. B., Studies of lung volumes and intrapulmonary mixing: normal lung volumes. Unpublished data.

4. Bateman, J. B., Studies of lung volumes and intrapulmonary mixing: nitrogen clearance curves: the apparent respiratory dead space and its significance. Unpublished data.

5. Krogh, August, and Lindhard, J., Measurements of the blood flow through the lungs of man. Skandinav. Arch. f. Physiol., 1912, 27, 100.

6. Krogh, August, A bicycle ergometer and respiration apparatus for the experimental study of muscular work. Skandinav. Arch. f. Physiol., 1913, 30, 375. 